\title{
Polymorphism of SREBP1 is associated with beef fatty acid composition in Simmental bulls
}

L. Xu*, L.P. Zhang*, Z.R. Yuan, L.P. Guo, M. Zhu, X. Gao, H.J. Gao, J.Y. Li and S.Z. Xu

Laboratory of Molecular Biology and Bovine Breeding, The Key Laboratory for Farm Animal Genetic Resources and Utilization, Ministry of Agriculture of China, Institute of Animal Science, Chinese Academy of Agricultural Sciences, Beijing, China

*These authors contributed equally to this study.

Corresponding authors: S.Z. Xu / J.Y. Li

E-mail: xuli_ts@163.com

Genet. Mol. Res. 12 (4): 5802-5809 (2013)

Received February 26, 2013

Accepted June 26, 2013

Published November 22, 2013

DOI http://dx.doi.org/10.4238/2013.November.22.7

\begin{abstract}
The sterol regulatory element binding factor 1 gene (SREBP 1) plays an important role in the biosynthesis of fatty acids and cholesterol, and in lipid metabolism. The objective of this study was to investigate the effect of genetic polymorphisms of SREBPI on the fatty acid composition of muscle and carcass traits in Simmental bulls and Snow Dragon black cattle. The 84-bp insertion/deletion (indel) in intron 5 of the bovine SREBP1 gene was genotyped by polymerase chain reaction to investigate its associations with traits. The results showed that the 84-bp indel in intron 5 was significantly associated with palmitoleic acid (C16:1), stearic acid (C18:0), saturated fatty acids (SFA), triglycerides (TAG), and the C16 index in Simmental bulls (P $<0.05)$. Cattle with the LL genotype had higher palmitic acid (C16:1), triglycerides, and C16 index but lower stearic acid (C18:0) and SFA compared to those with the LS genotype $(\mathrm{P}<0.05)$. In conclusion, the 84-bp indel of SREBP1 could be used as a genetic marker for selecting Simmental breeding stock for healthier fatty acid composition.
\end{abstract}

Key words: $S R E B P 1$ gene; Insertion/deletion mutation; Polymorphism; Fatty acid composition; Simmental bulls; Snow Dragon black cattle 


\section{INTRODUCTION}

The fatty acid composition of beef is of great research interest owing to its implications for human health. A high intake of saturated fatty acids (SFA) can result in elevated plasma cholesterol, which contributes to cardiovascular disease (Bronte-Stewart et al., 1956). SFA are the main fatty acids found in meat, and approximately $80 \%$ of the fatty acid in beef is composed of palmitic (C16:0), stearic (C18:0), and oleic acid (C18:1), while the remaining $20 \%$ is distributed among 30 different fatty acids (Whetsell et al., 2003). Among the SFA, lauric (C12:0), myristic (C14:0), and palmitic acid (C16:0) are considered to have the most harmful cardiovascular effects (Mozaffarian et al., 2005), whereas stearic acid is not detrimental to human health (Bonanome and Grundy, 1988). Conversely, monounsaturated (MUFA) and polyunsaturated (PUFA) fatty acids increase hepatic low-density lipoprotein (LDL) receptor activity, thereby decreasing the circulating concentration of LDL cholesterol (Woollett et al., 1992). In addition to marbling, the fatty acid composition is the main factor defining meat quality parameters, such as texture and taste, and can be improved by an increased MUFA to SFA ratio (Yang et al., 1999). Recent studies with animal models showed that one of the trans fatty acid isomers also found in beef, vaccenic acid (C18:1), may also have a number of potential health benefits (Wang et al., 2008; Bassett et al., 2010). Therefore, increasing the concentrations of beneficial fatty acids of beef would add value to beef products.

Unlike that of non-ruminants, the fatty acid composition of beef is much less dependent on diet. The sterol regulatory element binding factor 1 gene (SREBP1) plays an important role in determining the fatty acid composition of beef. SREBPI is a member of the basic helix-loophelix-leucine zipper family of transcription factors that is involved in adipocyte differentiation, biosynthesis of cholesterol and fatty acids (Brown and Goldstein, 1997), as well as playing an essential role in energy homeostasis. In humans, this gene family consists of two genes: one is SREBP1, which has been mapped to chromosome 17 (Hua et al., 1995) and contributes to fat synthesis (Shimano et al., 1997), and SREBP2 is on chromosome 22 (Miserez et al., 1997) and is related with cholesterol synthesis (Horton et al., 1998). The objective of this study was to investigate the genetic polymorphisms of SREBP1, and to evaluate their effects on fatty acid composition of muscle and carcass traits in Simmental bulls and Snow Dragon black cattle.

\section{MATERIAL AND METHODS}

\section{Animals and sample collection}

The experiment was carried out with 442 animals - 314 Simmental bulls and 128 Snow Dragon black cattle. For genomic DNA extraction to estimate the gene frequencies of SREBP1, blood samples of Simmental bulls were collected from the JinWei FuRen Breeding Farm, Inner Mongolia Autonomous Region, and muscle samples of Snow Dragon black cattle were collected from the Snow Dragon Beef Company, Dalian, Liaoning Province. Their feeding conditions, slaughter age, foraging concentration and intake, and fattening period were tightly controlled. Carcass and meat quality traits were measured according to the criterion GB/T17238-1998 of the Cutting Standard of Fresh and Chilled Beef in China (China Standard Publishing House). Samples of the longissimus muscle of the back were collected from the left side of the carcasses between the 12th and 13th ribs (approximately $11 \mathrm{~cm}$ thick) at $24 \mathrm{~h}$ post- 
harvest. The marbling score for quality grade was evaluated on a cross section of the longissimus muscle at the 12 to 13 rib interface, which was scored on a scale of 1-6. Fatty acid components were measured from muscle tissues by a hydrolytic extraction method according to Sukhita and Palmquist (1998) using a gas chromatograph (GC-2014C, Shimadzu). Fatty acid components were measured according to the criterion GB/T22223-2008 Fat (total, saturated, and unsaturated) in Food, using the hydrolytic extraction gas chromatography method. All experimental protocols and animal care were performed according to authorization granted by the Chinese Ministry of Agriculture.

\section{Genotyping}

We applied polymerase chain reaction (PCR) amplification to detect the 84-bp insertion/deletion (indel) in intron 5 of the bovine SREBPl gene. The following primers were used: forward, 5'-CCACAACGCCATCGAGAAACGCTAC-3'; reverse, 5'-GGCCTTCCCTGACCNC CCAACTTAG-3'. PCR was performed in $25-\mu \mathrm{L}$ reaction volumes with $50 \mathrm{ng}$ genomic DNA as a template, $2.5 \mu \mathrm{L}$ 10X PCR buffer (100 mM Tris-HCl, $15 \mathrm{mM} \mathrm{MgCl}, 500 \mathrm{mM} \mathrm{KCl}, \mathrm{pH}$ 8.6), $2.0 \mu \mathrm{L} 2 \mathrm{mM}$ dNTP mix, $0.6 \mu \mathrm{L} 10 \mathrm{pM}$ each primer, and $0.4 \mathrm{U}$ Taq polymerase (Takara Biotechnology, Japan). The thermal cycling conditions were as follows: $94^{\circ} \mathrm{C}$ for $10 \mathrm{~min}$ for initial denaturation, 35 cycles at $94^{\circ} \mathrm{C}$ for $30 \mathrm{~s}, 30 \mathrm{~s}$ annealing at $63.9^{\circ} \mathrm{C}, 30 \mathrm{~s}$ extension at $72^{\circ} \mathrm{C}$, and a final extension for $10 \mathrm{~min}$ at $72^{\circ} \mathrm{C}$. The resulting fragments were analyzed on $3 \%$ agarose gel with ethidium bromide in $1 \mathrm{X}$ Tris-borate-ethylenediaminetetraacetic acid (TBE) buffer.

\section{Statistical analysis}

Genotype and allele frequencies were calculated according to Falconer and Mackay (1996). A chi square test was performed to test for Hardy-Weinberg equilibrium (HWE) at each locus by comparing expected and observed genotype frequencies (Falconer and Mackay, 1996). For each animal, 22 traits were considered, including total lipids, individual fatty acids, the sum of SFA, MUFA, PUFA, together with the $\mathrm{Cn}$ index $=\mathrm{Cn}: 1 /(\mathrm{Cn}: 0+\mathrm{Cn}: 1)$, where $\mathrm{N}=$ 14,16 , or 18, the total desaturation index, estimated as MUFA / (MUFA + SFA), marbling, fat color, back fat thickness, and the health index (HI), which was calculated as the inverse of the atherogenic index proposed by Ulbricht and Southgate (1991) as shown below:

$$
\mathrm{HI}=\frac{\sum \text { MUFA }+\sum \text { PUFA }}{4 \times \mathrm{C} 14: 0+\mathrm{C} 16: 0}
$$

Associations between individual single nucleotide polymorphisms (SNPs) and fatty acid measurements were evaluated using the GLM Mode of SAS for windows 9.1.3. The linear model used was as follows:

$$
\mathrm{y}_{\mathrm{ijm}}=\mu+\mathrm{Y}_{\mathrm{i}}+\mathrm{M}_{\mathrm{j}}+\mathrm{G}_{\mathrm{m}}+\mathrm{W}_{\mathrm{ijm}}+\mathrm{e}_{\mathrm{ijm}} \quad \text { (Equation 2) }
$$

where $y_{i j m}$ is the observation of the fatty acid measurement traits; $\mu$ is the overall mean, $Y_{i}$ is the effect of year of calving, $M_{j}$ is the effect of month of calving, $G_{m}$ is the effect of genotype, and $e_{i j m}$ is the random residual effect. 


\section{RESULTS}

\section{DNA polymorphism identification and genotyping}

We identified the 84-bp indel in SREBP1 in Simmental bulls and Snow Dragon black cattle. The 84-bp polymorphism in intron 5 of the SREBP1 gene was detected directly from amplified products. Genotyping was carried out based on the different lengths of PCR products in which the $\mathrm{S}$ (deletion/short type, $348 \mathrm{bp}$ ) and $\mathrm{L}$ (insertion/long type, $432 \mathrm{bp}$ ) types were detected (Figure 1). In the 314 Simmental bulls, the genotype frequencies were 0.675 (LL type), 0.316 (LS type), and 0.010 (SS type), and the estimated allele frequencies were 0.832 and 0.168 for L and S alleles, respectively. We also investigated 128 Snow Dragon black cattle to determine the frequency of minor alleles, which was 0.039 (Table 1). The genotype frequencies of the two breeds were all in agreement with HWE for each polymorphism $(\mathrm{P}>0.05)$.

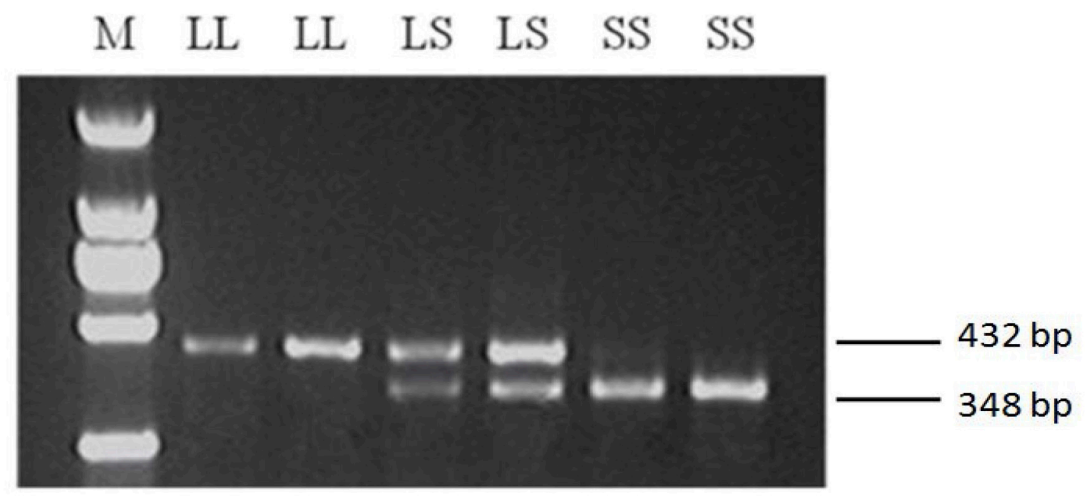

Figure 1. Genotyping of the SREBP1 indel polymorphism in intron 5. The arrowheads show the size of DNA fragment (bp). These DNA fragments were fractionated using 3\% agarose gel.

Table 1. Genotype and allele frequencies of the SREBP1 gene in Simmental bulls and Snow Dragon black cattle.

\begin{tabular}{|c|c|c|c|c|c|c|c|c|c|}
\hline \multirow[t]{2}{*}{ Breed } & \multirow[t]{2}{*}{ Gene } & \multirow[t]{2}{*}{$\mathrm{N}$} & \multicolumn{3}{|c|}{ Genotype frequency } & \multicolumn{2}{|c|}{ Allele frequency } & \multirow[t]{2}{*}{$H_{\mathrm{E}}$} & \multirow[t]{2}{*}{ PIC } \\
\hline & & & LL & LS & SS & $\mathrm{L}$ & $\mathrm{S}$ & & \\
\hline Simmental bulls & SREBP 84-bp indel & 314 & $0.675(212)$ & $0.316(99)$ & $0.010(3)$ & 0.832 & 0.168 & 0.279 & 0.240 \\
\hline Snow Dragon black cattle & SREBP 84-bp indel & 128 & $0.617(79)$ & $0.344(44)$ & $0.039(5)$ & 0.789 & 0.211 & 0.333 & 0.278 \\
\hline
\end{tabular}

\section{Association analysis with fatty acid composition and carcass traits}

The indel genotyping was performed on 314 samples of Simmental bulls, and a general linear model was used to estimate the association between the genotypes and fatty acid composition. The 84-bp length polymorphism in $S R E B P 1$ was investigated for associations with beef fatty acid composition. The SREBPI genotypes were associated with palmitoleic acid (C16:1), stearic acid (C18:0), SFA, triglycerides, and the C16 index in Simmental bulls (Table 2). Levels of palmitoleic acid (C16:1), triglycerides, and C16 index were higher in cattle with genotype LL than those with genotype LS $(\mathrm{P}<0.05)$. The concentration of stearic acid $(\mathrm{C} 18: 0)$ 
and the SFA content were $26.1 \%$ and $1.19 \%$ lower in the LL genotype compared to the LS genotype, respectively $(\mathrm{P}<0.05)$. Because only three individuals with the $\mathrm{SS}$ genotype were found, we here only compare individuals with LL and LS genotypes. Moreover, significant differences were observed between the SREBP1 genotypes and C14:0, C14:1, C16:0, C17:0, C18:3, 18:1, 18:2, MUFA, PUFA, C14 index, C18 index, total index and HI.

Table 2. Effect of 84-bp indel in intron 5 of the SREBP1 gene on fatty acid composition in Simmental bulls.

\begin{tabular}{|c|c|c|c|c|}
\hline \multirow[t]{2}{*}{ Trait } & \multicolumn{3}{|c|}{ 84-bp indel } & \multirow[t]{2}{*}{$\mathrm{P}$} \\
\hline & LL & LS & SS & \\
\hline Myristic acid (C14:0) & $2.11 \pm 0.08$ & $1.91 \pm 0.15$ & $1.78 \pm 0.58$ & 0.5276 \\
\hline Tetradecylenic acid (C14:1) & $0.06 \pm 0.03$ & $0.06 \pm 0.05$ & $0.06 \pm 0.2$ & 0.979 \\
\hline Palmitic acid (C16:0) & $32.2 \pm 1.29$ & $35.08 \pm 2.33$ & $50.08 \pm 9.07$ & 0.1287 \\
\hline Palmitoleic acid (C16:1) & $2.08 \pm 0.19$ & $0.47 \pm 0.34$ & $1.79 \pm 1.35$ & $0.0160 *$ \\
\hline Daturic acid $(\mathrm{C} 17: 0)$ & $0.79 \pm 0.10$ & $1.04 \pm 0.20$ & $1.40 \pm 0.80$ & 0.4980 \\
\hline Stearic acid (C18:0) & $27.58 \pm 1.81$ & $37.34 \pm 3.28$ & $50.61 \pm 12.75$ & $0.0429^{*}$ \\
\hline Oleic acid $(18: 1)$ & $21.77 \pm 1.66$ & $12.77 \pm 3.0$ & $13.521 \pm 1.68$ & 0.1182 \\
\hline Linoleic acid (18:2) & $7.48 \pm 0.90$ & $4.72 \pm 1.64$ & $0.70 \pm 6.38$ & 0.3131 \\
\hline$\gamma$-Linoleic acid (C18:3) & $0.41 \pm 0.16$ & $0.63 \pm 0.29$ & $0.41 \pm 1.13$ & 0.877 \\
\hline SFA & $62.69 \pm 2.60$ & $76.11 \pm 4.90$ & $104.94 \pm 18.6$ & $0.0399 *$ \\
\hline MUFA & $23.90 \pm 1.79$ & $13.36 \pm 3.25$ & $21.39 \pm 12.76$ & 0.1091 \\
\hline PUFA & $8.54 \pm 1.20$ & $6.13 \pm 2.18$ & $7.00 \pm 8.49$ & 0.7382 \\
\hline TAG & $0.98 \pm 0.07$ & $0.59 \pm 0.13$ & $0.37 \pm 0.54$ & $0.0181^{*}$ \\
\hline C14 index & $0.02 \pm 0.01$ & $0.02 \pm 0.02$ & $0.02 \pm 0.09$ & 0.9760 \\
\hline C16 index & $0.07 \pm 0.01$ & $0.02 \pm 0.01$ & $0.01 \pm 0.05$ & $0.0168^{*}$ \\
\hline C18 index & $0.45 \pm 0.03$ & $0.25 \pm 0.06$ & $0.31 \pm 0.24$ & 0.1405 \\
\hline Total index & $0.28 \pm 0.02$ & $0.16 \pm 0.04$ & $0.22 \pm 0.16$ & 0.1509 \\
\hline $\mathrm{HI}$ & $0.89 \pm 0.09$ & $0.59 \pm 0.16$ & $0.48 \pm 0.65$ & 0.4003 \\
\hline
\end{tabular}

Values are reported as $\mathrm{LSM} \pm \mathrm{SE}$. Fatty acid contents are reported as $\mathrm{g} / 100 \mathrm{~g}$ total fatty acids. SFA $=$ total saturated fatty acids; MVFA = total monounsaturated fatty acids; PUFA = total polyunsaturated fatty acids; TAG = triglycerides; $\mathrm{HI}=$ health index. $* \mathrm{P}<0.05$.

We also investigated the polymorphisms' associations with carcass traits in Simmental bulls and Snow Dragon black cattle (Table 3). Back fat thickness in Snow Dragon black cattle with the SS genotype was 19.89 and $21.94 \%$ higher than those of the LL and LS genotypes, respectively $(\mathrm{P}<0.05)$. No significant differences were observed between the SREBPI genotypes and other traits in Snow Dragon black cattle and Simmental bulls.

Table 3. Effect of 84-bp indel in intron 5 of the SREBP1 gene on carcass traits on Simmental bulls and Snow Dragon black cattle.

\begin{tabular}{|c|c|c|c|c|c|c|c|c|}
\hline \multirow[t]{2}{*}{ Trait } & \multicolumn{4}{|c|}{ Simmental bulls } & \multicolumn{4}{|c|}{ Snow Dragon black cattle } \\
\hline & LL & LS & SS & $\mathrm{P}$ & LL & LS & SS & $\mathrm{P}$ \\
\hline Marbling & $5.07 \pm 0.14$ & $5.35 \pm 0.25$ & $5.07 \pm 1.0$ & 0.978 & $2.66 \pm 0.21$ & $2.93 \pm 0.27$ & $2.65 \pm 0.62$ & 0.164 \\
\hline Fat color & $2.05 \pm 0.10$ & $1.94 \pm 0.14$ & $2.12 \pm 0.75$ & 0.897 & $3.44 \pm 0.19$ & $3.47 \pm 0.25$ & $3.49 \pm 0.57$ & 0.217 \\
\hline Backfat thickness & $0.18 \pm 0.01$ & $0.20 \pm 0.01$ & $0.10 \pm 0.06$ & 0.415 & $1.57 \pm 0.19$ & $1.53 \pm 0.17$ & $1.96 \pm 0.41$ & $0.022 *$ \\
\hline
\end{tabular}

Values are reported as $\mathrm{LSM} \pm \mathrm{SE} . * \mathrm{P}<0.05$.

\section{DISCUSSION}

At present, breeding goals are changing from high yield to high meat quality traits (van Wijk et al., 2005), and are increasingly associated with human health. Performing asso- 
ciation studies with a candidate gene is a step toward better comprehension of the genetic basis of productive traits (Óvilo et al., 2006). SREBP1 is an important candidate gene for selecting carcass and meat quality traits in cattle breeding research. However, few studies on this gene have been conducted to date in cattle. In the present study, SREBP1 polymorphisms were detected by PCR in Simmental bulls and Snow Dragon black cattle.

$S R E B P 1$ belongs to the family of basic helix-loop-helix-leucine zipper transcription factors that bind to the sterol regulatory element (DNA sequence TCACNCCAC), and acts as a key regulatory element for fatty acid biosynthesis and cholesterol homeostasis (Felder et al., 2005). In humans, a precursor of SREBP is organized into three domains: 1) transactivation domain in the $\mathrm{NH}_{2}$ terminal with a serine/proline-rich bHLH-LZ region; 2) transmembranespanning segments bound to the lumen of the endoplasmic reticula; 3 ) regulatory domain in the COOH terminal (Brown and Goldstein, 1999; Shimano, 2001; Eberlé et al., 2004). The three domains in the bovine SREBP1 protein have also been confirmed based on comparison of amino acid sequences between bovine and human SREBP1.

Our study of the 84-bp indel in Simmental bulls and Snow Dragon black cattle identified three different genotypes, which are in accordance with previous results reported by Hoashi et al. (2007) in Japanese Black cattle. Furthermore, in a study of five different breeds, this polymorphism was only found in the Limousine breed, suggesting that it might be a breed-specific phenomenon and may not be segregating widely in different cattle populations (Bhuiyan et al., 2009). In the present study, Snow Dragon black cattle showed a slightly higher frequency of the SS genotype compared to Simmental bulls, which may be due to its long history of selective breeding.

The present study also showed that the genotype LL of SREBP1 resulted in an increase in $\mathrm{C} 16$ and a decrease in C18 and SFA proportion in the muscle. In contrast, the stearic acid concentration was $6.30 \%$ lower in the SS genotype compared to the LL genotype (P< 0.05), but the linoleic and PUFA contents were 11.06 and $12.20 \%$ higher in SS compared to LL (Bhuiyan et al., 2009). Several studies have reported associations between SREBP1 and fatty acid composition and carcass traits. The $\mathrm{S}$ type contributed to a $1.3 \%$ increase in the MUFA proportion and a $1.6^{\circ} \mathrm{C}$ lower melting point of intramuscular fat (Hoashi et al., 2007). Steers with the LL genotype had a $23.0 \%$ higher concentration of C17:1 than that of steers with the LS genotypes $(\mathrm{P}=0.013)$ (Han et al., 2013).

Because the 84-bp indel exists in intron 5 of the bovine SREBP1 gene, it may affect the translation efficiency of SREBP1 itself. This suggests that the indel might indirectly contribute to fat-quality characteristics in cattle. Previous studies have reported associations between intron regions of the tumor necrosis factor receptor gene and the lipoprotein lipase gene with adipocyte metabolism (Benjafield et al., 2001; Pasalic et al., 2001). The inserted 84-nucleotide fragment might function like a microRNA in regulating transcription levels of its downstream genes, which would indirectly affect fatty acid traits.

Previous studies in humans have shown that SREBPla gene polymorphisms were related to risks of cardiovascular disease and hyperlipoproteinemia (Miserez et al., 2001; Vedie et al., 2001). As in other mammals, there were no splice variants detected in the bovine $S R E B P 1$ gene, and it shows the most similarity with the human SREBPla sequence (Hoashi et al., 2007). Human SREBPla is a higher potential transcriptional activator than the other isoform, $S R E B P I \mathrm{c}$, due to its longer $\mathrm{NH}_{2}$-terminal trans-activation domain (Shimano et al., 1997). 
Stearoyl-CoA desaturase gene (SCD1) is a rate-limiting enzyme responsible for the conversion of SFA into MUFA. This enzyme, located in the endoplasmic reticulum, inserts a double bond between carbons 9 and 10 of the fatty acyl chain, so affecting the fatty acid composition of membrane phospholipids, triglycerides and cholesterol esters (Ntambi and Miyazaki, 2004). Our previous study showed that up-regulation of the SREBP1 gene in bovine fetal fibroblasts results in an expression of SCD mRNA. This result indicates that as a member of the family of transcription factors, SREBPI also affects the $S C D$ gene (Xu et al., 2013).

The present study is the first to determine the full-length coding sequence of the SREBP1 gene in our resource population of Simmental, and to detect genetic polymorphisms in the genomic region. In this study, we demonstrated that the bovine SREBPI polymorphism is associated with proportions of C16:0, C18:0, SFA, and TAG in the fat composition. This result indicates that genotyping of $S R E B P 1$ is a useful method for the selection of favorably flavored beef, as well as contributing SCD genotype information for the beef industry, which is relevant in controlling human lipid metabolism disease. Since the association was low due to the relatively small sample size, further research will be necessary to study these SNPs in larger populations and in other breeds. Furthermore, the effects should be investigated at the cellular level to better clarify the role of SREBP1 on fatty acid composition and carcass traits.

\section{ACKNOWLEDGMENTS}

Research supported by the Twelfth "Five-Year" National Science and Technology Support Project (\#2011BAD28B04), the New Variety of Transgenic Organism Great Breeding Program (\#2008ZX08007-002), the Agriculture Ministry special project (\#CARS-38), the National Natural Science Foundation of China (\#31201782, \#31272428, \#31201768, \#31372294), the Beijing Natural Science Foundation (\#6133033), and the Chinese National Programs for High Technology Research and Development (\#2013AA102505-4).

\section{REFERENCES}

Bassett CM, Edel AL, Patenaude AF, McCullough RS, et al. (2010). Dietary vaccenic acid has antiatherogenic effects in LDLr $^{-/}$mice. J. Nutr. 140: 18-24.

Benjafield AV, Wang XL and Morris BJ (2001). Tumor necrosis factor receptor 2 gene (TNFRSF1B) in genetic basis of coronary artery disease. J. Mol. Med. 79: 109-115.

Bhuiyan MSA, Yu SL, Jeon JT, Yoon D, et al. (2009). DNA polymorphisms in SREBP1 and FASN genes affect fatty acid composition in Korean cattle (Hanwoo). Asian-Aust. J. Anim. Sci. 22: 765-773.

Bonanome A and Grundy SM (1988). Effect of dietary stearic acid on plasma cholesterol and lipoprotein levels. N. Engl. J. Med. 318: 1244-1248.

Bronte-Stewart B, Antonis A, Eales L and Brock JF (1956). Effects of feeding different fats on serum-cholesterol level. Lancet 270: 521-526.

Brown MS and Goldstein JL (1997). The SREBP pathway: regulation of cholesterol metabolism by proteolysis of a membrane-bound transcription factor. Cell 89: 331-340.

Brown MS and Goldstein JL (1999). A proteolytic pathway that controls the cholesterol content of membranes, cells, and blood. Proc. Natl. Acad. Sci. U. S. A. 96: 11041-11048.

Eberlé D, Hegarty B, Bossard P, Ferre P, et al. (2004). SREBP transcription factors: master regulators of lipid homeostasis. Biochimie 86: 839-848.

Falconer DS and Mackay TFC (1996). Introduction to Quantitative Genetic. 4th edn. Harlow, Longman.

Felder TK, Klein K, Patsch W and Oberkofler H (2005). A novel SREBP-1 splice variant: tissue abundance and transactivation potency. Biochim. Biophys. Acta 1731: 41-47. 
Han C, Vinsky M, Aldai N, Dugan ME, et al. (2013). Association analyses of DNA polymorphisms in bovine SREBP-1, LXR $\alpha$, FADS1 genes with fatty acid composition in Canadian commercial crossbred beef steers. Meat Sci. 93 : 429-436.

Hoashi S, Ashida N, Ohsaki H, Utsugi T, et al. (2007). Genotype of bovine sterol regulatory element binding protein-1 (SREBP-1) is associated with fatty acid composition in Japanese Black cattle. Mamm. Genome 18: 880-886.

Horton JD, Shimomura I, Brown MS, Hammer RE, et al. (1998). Activation of cholesterol synthesis in preference to fatty acid synthesis in liver and adipose tissue of transgenic mice overproducing sterol regulatory element-binding protein-2. J. Clin. Invest. 101: 2331-2339.

Hua X, Wu J, Goldstein JL, Brown MS, et al. (1995). Structure of the human gene encoding sterol regulatory element binding protein-1 (SREBF1) and localization of SREBF1 and SREBF2 to chromosomes 17p11.2 and 22q13. Genomics 25: 667-673.

Miserez AR, Cao G, Probst LC and Hobbs HH (1997). Structure of the human gene encoding sterol regulatory element binding protein 2 (SREBF2). Genomics 40: 31-40.

Miserez AR, Muller PY, Barella L, Schwietert M, et al. (2001). A single-nucleotide polymorphism in the sterol-regulatory element-binding protein 1c gene is predictive of HIV-related hyperlipoproteinaemia. AIDS 15: 2045-2049.

Mozaffarian D, Ascherio A, Hu FB, Stampfer MJ, et al. (2005). Interplay between different polyunsaturated fatty acids and risk of coronary heart disease in men. Circulation 111: 157-164.

Ntambi JM and Miyazaki M (2004). Regulation of stearoyl-CoA desaturases and role in metabolism. Prog. Lipid. Res. 43: 91-104.

Óvilo C, Fernández A, Rodríguez MC, Nieto M, et al. (2006). Association of MC4R gene variants with growth, fatness, carcass composition and meat and fat quality traits in heavy pigs. Meat Sci. 73: 42-47.

Pasalic D, Sertic J, Kunovic B, Milicevic Z, et al. (2001). Lipoprotein lipase gene polymorphism and lipid profile in patients with hypertriglyceridemia. Croat Med. J. 42: 517-522.

Shimano H (2001). Sterol regulatory element-binding proteins (SREBPs): transcriptional regulators of lipid synthetic genes. Prog. Lipid Res. 40: 439-452.

Shimano H, Horton JD, Shimomura I, Hammer RE, et al. (1997). Isoform 1c of sterol regulatory element binding protein is less active than isoform 1a in livers of transgenic mice and in cultured cells. J. Clin. Invest. 99: 846-854.

Sukhija PS and Palmquist DL (1998). Rapid method for determination of total fatty acid and composition of feed stuffs and feeds. Am. Chem. Soc. 36: 5.

Ulbricht TL and Southgate DA (1991). Coronary heart disease: seven dietary factors. Lancet 338: 985-992.

van Wijk HJ, Arts DJ, Matthews JO, Webster M, et al. (2005). Genetic parameters for carcass composition and pork quality estimated in a commercial production chain. J. Anim. Sci. 83: 324-333.

Vedie B, Jeunemaitre X, Megnien JL, Atger V, et al. (2001). A new DNA polymorphism in the 5' untranslated region of the human SREBP-1a is related to development of atherosclerosis in high cardiovascular risk population. Atherosclerosis 154: 589-597.

Wang Y, Lu J, Ruth MR, Goruk SD, et al. (2008). Trans-11 vaccenic acid dietary supplementation induces hypolipidemic effects in JCR:LA-cp rats. J. Nutr. 138: 2117-2122.

Whetsell MS, Rayburn EB and Lozier JD (2003). Human Health Effects of Fatty Acids in Beef. A report on "Pasture Based Beef Systems for Appalachia", West Virginia University, Morgantown.

Woollett LA, Spady DK and Dietschy JM (1992). Saturated and unsaturated fatty acids independently regulate low density lipoprotein receptor activity and production rate. J. Lipid. Res. 33: 77-88.

Xu L, Guo LP, Zhu M, Gao X, et al. (2013). Effect of the overexpression of sterol regulatory element binding factor 1 gene increases lipid droplet formation in bovine fetal fibroblasts. China Anim. Husbandry Vet. Med. 40: 133-139.

Yang A, Larsen TW, Smith SB and Tume RK (1999). $\Delta^{9}$ desaturase activity in bovine subcutaneous adipose tissue of different fatty acid composition. Lipids 34: 971-978. 